\title{
Valor alimentício do capim marandu, adubado ou consorciado com amendoim forrageiro, e características da carcaça de bovinos de corte submetido à pastejo rotacionado
}

\section{Feeding value of grass fertilized marandu or intercropped with peanut and carcass characteristics of beef cattle under rotational grazing}

\author{
PEREIRA, Marcelo Mota ${ }^{1}$; REZENDE, Cláudia de Paula ${ }^{3 *}$; PEDREIRA, Márcio \\ Santos $^{2}$; PEREIRA, José Marques ${ }^{3}$; MACEDO, Thasia Martins ${ }^{4}$; SILVA, Herymá \\ Giovane de Oliveira ${ }^{2}$; BORGES, Augusto Magno Ferreira ${ }^{3}$; SILVA, Antonio Márcio \\ Pereira $^{2}$
}

\footnotetext{
${ }^{1}$ Universidade Estadual do Sudoeste da Bahia, Programa de Pós-Graduação em Zootecnia, Itapetinga, Bahia, Brasil.

${ }^{2}$ Universidade Estadual do Sudoeste da Bahia, Departamento de Tecnologia Rural e Animal, Itapetinga, Bahia, Brasil.

${ }^{3}$ Comissão Executiva de Planejamento da Lavoura Cacaueira, Itabuna, Bahia, Brasil.

${ }^{4}$ Universidade Federal de Minas Gerais, Programa de Pós-Graduação em Zootecnia, Belo Horizonte, Minas Gerais, Brasil.

*Endereço para correspondência: claudiarezende49@gmail.com
}

\section{RESUMO}

Objetivou-se, com este estudo, avaliar a composição química do pasto de capim marandu consorciado com amendoim forrageiro ou adubado com $\mathrm{N}$ e as características das carcaças de bovinos de corte. A pastagem foi manejada sob pastejo rotacionado com lotação contínua, e carga animal variável, utilizando-se 16 novilhos da raça nelore. $\mathrm{Na}$ avaliação de produção de matéria seca verde total, foram observadas significâncias estatísticas entre os tratamentos e períodos avaliados, sendo que o tratamento com o consórcio apresentou uma maior média. A variável proteína bruta $(\mathrm{PB})$ apresentou significância entre os tratamentos e períodos avaliados. Os teores de nutrientes digestíveis totais (NDT) e fibras em detergente neutro (FDN) não apresentaram efeito significativo na avaliação da gramínea. Os períodos que apresentaram os menores ganhos médios diários (GMD) foram o quarto e sexto períodos. Para os teores de PB, NDT e FDN da leguminosa, o terceiro período foi o que apresentou as menores médias. Para as variáveis GMD, número de animais por dia (NAD), GPV, a estatística apresentou significância para a interação, sendo que o primeiro período do tratamento com o consórcio apresentou as maiores médias. No tratamento da adubação, as maiores taxas de lotação foram conseguidas nas estações onde ocorreram as adubações químicas. Foi observada significância estatística para a variável conformação na classificação das carcaças. O consórcio do amendoim forrageiro cv. Belmonte pode ser utilizado em substituição à adubação, com $120 \mathrm{~kg} / \mathrm{N} / \mathrm{ha}$, pois garante $\mathrm{o}$ mesmo ganho de peso por animal, sem alterar as características comerciais das carcaças.

Palavras-chave: desempenho, forragem, nitrogênio, produtividade

\section{SUMMARY}

The objective of this study was to evaluate the chemical composition of the pasture Brachiaria Brizantha intercropped with peanut or fertilized with $\mathrm{N}$ and carcass characteristics of beef cattle. The pasture was managed under rotational grazing with stocking continues, with variable stocking, using 16 Nellore bulls. In the evaluation of dry matter production total green significance was observed between treatments and periods evaluated, and treatment consortium presented a higher average. The variable crude 
Rev. Bras. Saúde Prod. Anim., Salvador, v.16, n.3, p.643-657 jul./set.., $2015 \quad \underline{\text { http://www.rbspa.ufba.br }}$ ISSN 15199940

protein showed significance between treatments and periods. The NDT and FDN had no significant effect on the evaluation of the grass. Periods had lower ADG were the 4th and 6th periods. For the PB, FDN and NDT legume 3rd period showed the lowest averages. For variables GMD, NAD, GPC showed statistical significance for the interaction, and the 1 st treatment period consortium submitted the highest averages. In the treatment of the largest fertilizer stocking rates were achieved in stations where chemical fertilization occurred. Statistical significance was observed for the variable conformation carcass classification. The consortium forage peanut cv. Belmonte may be using to replace fertilization with $120 \mathrm{~kg}$ / $\mathrm{N} /$ ha, as it ensures even weight gain per animal, without changing the commercial carcass traits.

Keywords: fertilization, legume, pasture, performance

\section{INTRODUÇÃO}

A pecuária vem tendo uma grande participação no mercado internacional, ocupando o segundo lugar na produção e o primeiro na exportação, tendo que atender, dentre outros, dois aspectos fundamentais. Uma grande vantagem é ter como base o sistema de criação a pasto; utilizando as plantas forrageiras, que constituem a base de alimentação do rebanho bovino, este sistema é tido como a forma mais barata e competitiva no mundo, entretanto, ele só é possível se a pastagem for produtiva, e o sistema de produção, sustentável.

$\mathrm{O}$ Brasil possui área e condições climáticas favoráveis ao desenvolvimento das pastagens. Contudo, apresenta pastagens com baixa capacidade de produção, suporte, manutenção e recuperação, caracterizando-se, assim, um quadro de pastagens degradadas (OLIVEIRA et al., 2009; CAVALLINI et al. 2010; FERNANDES et al., 2010).

A utilização de fertilizantes químicos é prática muito utilizada para aumento da produção forrageira, sendo que seu grau de eficiência depende das condições edafoclimáticas e técnicas associadas (VOLPE et al., 2008).

Em contrapartida, a consorciação com leguminosas apresenta-se como uma excelente alternativa para o produtor, sendo capaz de aumentar a qualidade da forragem oferecida aos animais; incrementar a produtividade das forrageiras.

As leguminosas forrageiras, ao realizarem a fixação biológica do nitrogênio, vão contribuir com a produção animal, levando a um aumento da produtividade e à sustentabilidade das pastagens (BARCELLOS et al., 2008).

Objetivou-se, com este estudo, avaliar a composição química e a produtividade do pasto, a produtividade animal e as características comerciais de carcaças de bovinos alimentados em pastagem de capim marandu consorciado com amendoim forrageiro ou adubado com $120 \mathrm{~kg} / \mathrm{N} / \mathrm{ha}$.

\section{MATERIAL E MÉTODOS}

A área experimental constou de 48 piquetes de 0,156 ha cada. Sendo 24 piquetes compostos por Brachiaria, capim marandu consorciado com Arachis, amendoim forrageiro cv. Belmonte, e 24 piquetes compostos por capim marandu adubado com $120 \mathrm{~kg}$ de $\mathrm{N} /$ ha, em pastejo rotacionado com sete dias de controle de altura de resíduo e 35 dias de descanso.

O período experimental foi de março de 2009 a julho de 2010, na Comissão Executiva de Planejamento da Lavoura Cacaueira" (CEPLAC), Itabela. A área está sob o domínio do ecossistema de Mata Atlântica e o clima local é uma transição entre os tipos Af e Am, 
Rev. Bras. Saúde Prod. Anim., Salvador, v.16, n.3, p.643-657 jul./set.., $2015 \quad \underline{\text { http://www.rbspa.ufba.br }}$

segundo a classificação de Köppen, com precipitação anual de $1311 \mathrm{~mm}$ e temperatura média de $25^{\circ} \mathrm{C}$, sem estação seca definida (Figura 1). O solo é um Ultisol (Typic Paleudult fine-loamy, kaolinitic, isohyperthermic), arenoso $(>700 \mathrm{~g}$ de $\operatorname{areia} / \mathrm{kg})$ nos $20 \mathrm{~cm}$ superficiais. As avaliações de oferta e qualidade de forragem verde foram realizadas nas duas pastagens, de 16.03.2009 a 17.07.2010, totalizando 488 dias de observações, e agrupadas de forma a se ter seis períodos distintos em estudo (Tabela 1).

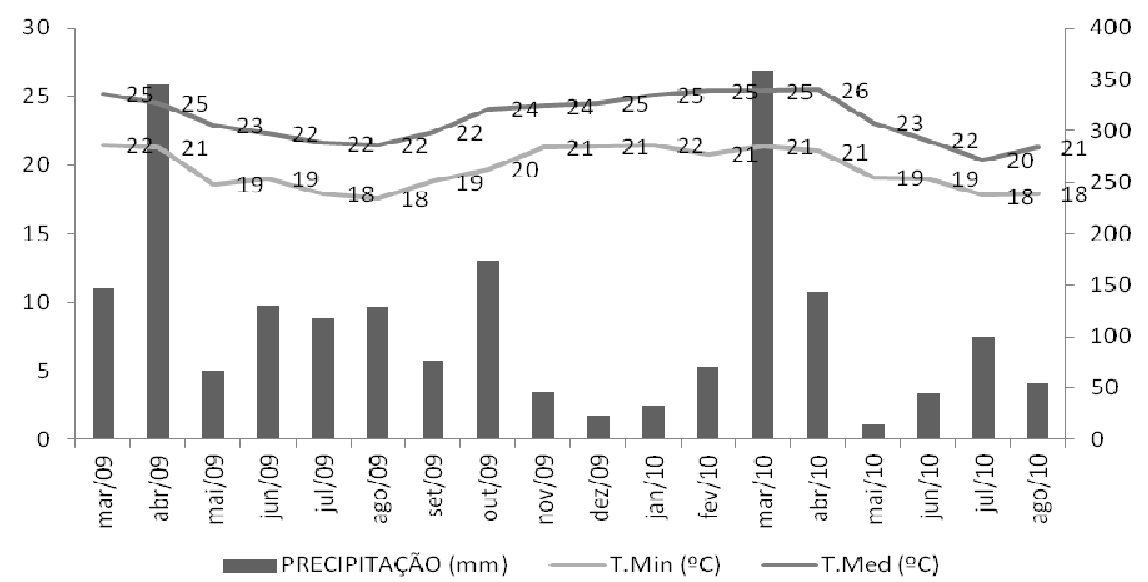

Figura 1. Precipitação pluviométrica, temperatura mínima e temperatura média durante o período experimental

Tabela 1. Distribuição dos períodos experimentais

\begin{tabular}{lc}
\hline Primeiro período & Março a Maio/2009 \\
Segundo período & Junho a Setembro/2009 \\
Terceiro período & Outubro a Dezembro 2009 \\
Quarto período & Janeiro a Fevereiro/2010 \\
Quinto período & Março a Junho/2010 \\
Sexto período & Junho a Julho/2010 \\
\hline
\end{tabular}

Durante o experimento, foi possível fazer três adubações de cobertura, limitadas principalmente pelas condições climáticas, ou seja, precipitação e temperatura adequadas para se obter maior eficiência no uso do fertilizante nitrogenado. A primeira fertilização de manutenção ocorreu no primeiro período, aplicando-se $20 \mathrm{~kg}$ de $\mathrm{P}_{2} \mathrm{O}_{5} / \mathrm{ha} ; 50 \mathrm{~kg}$ de $\mathrm{K}_{2} \mathrm{O} / \mathrm{ha}$ e $40 \mathrm{~kg} / \mathrm{ha}$ de N. A segunda fertilização, com apenas a aplicação de $40 \mathrm{~kg} / \mathrm{ha} \mathrm{N}$, ocorreu no terceiro período. A terceira fertilização, na base de $20 \mathrm{~kg}$ de $\mathrm{P}_{2} \mathrm{O}_{5} / \mathrm{ha} ; 50 \mathrm{~kg}$ de $\mathrm{K}_{2} \mathrm{O} / \mathrm{ha}$ e $40 \mathrm{~kg} / \mathrm{ha}$ de $\mathrm{N}$, foi realizada no quinto período, utilizando, como fontes desses nutrientes, os fertilizantes superfosfato simples, cloreto de potássio e ureia, respectivamente.

Nas duas pastagens, foi utilizado $o$ pastejo rotacionado com carga flexível, em função de $4 \%$ de oferta de matéria seca de forragem verde, utilizando-se 16 animais fixos, e os demais variando em função da disponibilidade dessa forragem. Os animais utilizados foram da raça nelore, castrados com peso inicial médio de 240,18 $\pm 19,50 \mathrm{~kg}$. Os animais foram identificados com marcação a ferro quente, pesados e distribuídos de forma homogênea $\mathrm{e}$ aleatória nos piquetes, a fim de garantir as médias de peso corporal semelhantes entre os tratamentos.

Todos os animais foram submetidos ao controle de ecto e endoparasitas e às 
Rev. Bras. Saúde Prod. Anim., Salvador, v.16, n.3, p.643-657 jul./set.., $2015 \quad \underline{\text { http://www.rbspa.ufba.br }}$

vacinações, conforme calendário sanitário local; receberam água e suplemento mineral disponível ad libitum, em bebedouros e saleiros localizados nas áreas de descanso dos piquetes de alimentação, de forma que o consumo diário era limitado pela presença do cloreto de sódio nos suplementos.

As avaliações de oferta de forragem foram realizadas a cada 15 dias, com a finalidade de se estimar a disponibilidade de matéria seca (MS) de um piquete aleatoriamente escolhido na área experimental. Em cada piquete avaliado, foram tomadas seis amostras, utilizando um quadrado de $1,0 \mathrm{~m}^{2}$, lançado ao acaso. Os cortes da forragem foram feitos a $0,25 \mathrm{~m}$ de altura, formando as amostras compostas. As amostras compostas da forragem foram pesadas e, inicialmente, retirou-se uma subamostra de aproximadamente $250 \mathrm{~g}$ da forragem, constituída da mistura do material verde e material morto, para determinação da matéria seca de forragem total (MSFT). Retiraram-se, também, mais 2,0kg desse material, que foi separado em fração de matéria seca de forragem senescente (MSFS) e matéria seca de forragem verde (MSFV), e fração de amendoim forrageiro (AR); a fração verde da gramínea foi separada ainda em fração de matéria seca de lâmina foliar e colmos verdes (REZENDE et al. 2008). As frações separadas foram pesadas e secas em estufa de ventilação forçada a $65^{\circ} \mathrm{C}$ até peso constante. Esse material foi triturado em moinho do tipo Willey, em peneira com crivos de $1,0 \mathrm{~mm}$ de diâmetro.

As análises laboratoriais foram realizadas no laboratório de nutrição animal do departamento de tecnologia rural e animal. Nas amostras da forragem, foram realizadas análises químicas, conforme metodologias descritas por Silva \& Queiroz (2002).
O teor de FDN foi determinado pelo método de partição de fibras, proposto por Van Soest et al. (1994).

O teor de NDT foi determinado segundo equações propostas por Chandler (1990):

Gramíneas e silagem de grãos: \%NDT $105,2-0,68(\% \mathrm{FDN})$.

Leguminosas: $\% \mathrm{NDT}=86,2-0,51$ (\%FDN).

Os animais foram pesados no início e no final do experimento, com realizações de pesagens intermediárias a cada 28 dias para a avaliação do desempenho, sem jejum.

Para a condução das pesagens, foi utilizada uma instalação anexa à área de pastagem, constituindo-se de um curral de contenção e uma balança individual tipo eletrônica.

$\mathrm{O}$ ganho médio diário (GMD) foi determinado pela diferença entre o peso corporal inicial (PCi) e o peso corporal final (PCf), dividido pelo período experimental em dias de cada período.

A partir do GMD, foi calculado o ganho de peso corporal (GPC) em kg/ha, multiplicando-se o GMD dos testers pelo número de animais por dia (NAD) para cada período.

A determinação da taxa de lotação dos animais por tratamento foi obtida a partir do somatório dos dezesseis animais testers com os animais reguladores, de forma a atingir $4,0 \%$ de oferta de matéria seca de forragem verde, por dia e por hectare. A percentagem de oferta de forragem é a relação existente entre a produção de matéria seca de forragem verde para cada $100 \mathrm{~kg}$ de peso vivo animal por dia de pastejo por unidade de área.

Ao final do experimento, os animais foram pesados sem jejum de alimentos antes do embarque para o frigorífico.

Os mesmos foram abatidos por insensibilização via concussão cerebral, seguida de secção de veia jugular. No 
Rev. Bras. Saúde Prod. Anim., Salvador, v.16, n.3, p.643-657 jul./set.., $2015 \quad \underline{\text { http://www.rbspa.ufba.br }}$ ISSN 15199940

final da linha de abate, as carcaças foram divididas em duas metades simétricas e pesadas para obtenção do peso de carcaça quente (PCQ), sendo identificadas e encaminhadas à câmara de resfriamento por 24 horas à temperatura em torno de $0^{\circ} \mathrm{C}$. Após o período de resfriamento, as meias- carcaças foram novamente pesadas para obtenção do peso de carcaça fria (PCF).

Foi calculada a perda por resfriamento $(\mathrm{PPR})=(\mathrm{PCQ} / \mathrm{PCF})^{*} 100$. Após o resfriamento, utilizou-se o lado esquerdo da carcaça para avaliar as características quantitativas e qualitativas, segundo Müller (1980).

Tabela 2. Sistema de pontuação para a avaliação da conformação de carcaças e escala de pontos para avaliação do grau de marmoreio

\begin{tabular}{|c|c|c|c|c|c|c|c|}
\hline \multicolumn{8}{|c|}{ Conformação } \\
\hline & Mais & Média & Menos & & Mais & Média & Menos \\
\hline Superior & 18 & 17 & 16 & Regular & 9 & 8 & 7 \\
\hline Muito boa & 15 & 14 & 13 & Má & 6 & 5 & 4 \\
\hline Boa & 12 & 11 & 10 & Inferior & 3 & 2 & 1 \\
\hline \multicolumn{8}{|c|}{ Marmoreio } \\
\hline & Mais & Médio & Menos & & Mais & Médio & Menos \\
\hline Abundante & 18 & 17 & 16 & Pequeno & 9 & 8 & 7 \\
\hline Moderado & 15 & 14 & 13 & Leve & 6 & 5 & 4 \\
\hline Médio & 12 & 11 & 10 & Traços & 3 & 2 & 1 \\
\hline
\end{tabular}

Fonte: Muller 1980.

Textura (TXT): determinada pelo tamanho volume das fibras musculares e avaliada subjetivamente, através de uma escala de pontos (Tabela 3 ).

Coloração (COR): coloração apresentada pelo músculo após resfriamento das carcaças pelo período de 24 horas. Realizou-se o corte transversal do músculo Longissimus dorsi, na região entre a $12^{\mathrm{a}}$ e $13^{\mathrm{a}}$ costelas, e após 30 minutos fez-se a avaliação seguindo a escala de pontuação (Tabela 3 ).

Tabela 3. Escalas de pontos para avaliação da textura e da coloração da carne

\begin{tabular}{lclc}
\hline Textura & Pontos & Coloração & Pontos \\
\hline Muito fina & 5 & Vermelha viva & 5 \\
Fina & 4 & Vermelha & 4 \\
Levemente grosseira & 3 & Vermelha levemente escura & 3 \\
Grosseira & 2 & Vermelha escura & 2 \\
Muito grosseira & 1 & Escura & 1 \\
\hline
\end{tabular}

Fonte: Muller (1980)

Comprimento de carcaça (CC): compreende a distância desde o bordo cranial do osso do púbis até o bordo anterior da primeira costela, medida com trena ou fita métrica.

Comprimento da perna (CP): com o auxílio de um compasso de madeira 
Rev. Bras. Saúde Prod. Anim., Salvador, v.16, n.3, p.643-657 jul./set.., $2015 \quad \underline{\text { http://www.rbspa.ufba.br }}$ ISSN 15199940

com pontas metálicas, encontrou-se a distância compreendida entre o bordo anterior do osso do púbis e um ponto médio dos ossos da articulação do tarso. $\mathrm{Na}$ sequência, mediu-se esta distância com o auxílio de uma trena ou fita métrica.

Espessura do coxão (EC): através de um compasso de madeira com pontas metálicas, encontrou-se a distância compreendida entre a face lateral e a medial da porção superior do coxão que, posteriormente, foi medido com $\mathrm{o}$ auxílio de uma trena ou fita métrica.

Área de olho de lombo (AL): no lado esquerdo da carcaça, procedeu-se um corte transversal entre a $12^{\mathrm{a}}$ e $13^{\mathrm{a}}$ costelas, expondo-se o músculo Longissimus dorsi. Após isso, foi traçado o seu contorno em papel vegetal e, posteriormente, esta área foi medida com auxílio de um planímetro.

Espessura de gordura subcutânea (EG), em mm: determinada com um auxílio de um paquímetro digital, utilizando-se a média aritmética de duas medidas ao redor do músculo Longissimus dorsi exposto.

O delineamento experimental foi em delineamento inteiramente casualizado (DIC), com dezesseis repetições, em um esquema de parcelas subdivididas, nas quais foram estudadas as duas pastagens constituídas de capim marandu, adubação com $120 \mathrm{~kg} /$ ha de nitrogênio, e a consorciada com amendoim forrageiro, sendo, nas subparcelas, os seis períodos ou épocas de avaliação.

Os dados foram submetidos à análise de variância, utilizando-se o procedimento ANOVA (para dados balanceados) dos recursos do software estatístico statistical analysis system (SAS, 1996). As comparações de médias foram feitas utilizando-se o teste SNK a 5\% de significância.

\section{RESULTADOS E DISCUSSÃO}

Na Tabela 4, estão apresentados os valores da disponibilidade em matéria seca de forragem verde total (MSVT), obtidos no consórcio de capim marandu com amendoim forrageiro e no capim marandu fertilizado com $120 \mathrm{~kg} / \mathrm{N} / \mathrm{ha}$, e observa-se que houve diferenças estatisticamente significantes $(\mathrm{P}<0,05)$ para as médias entre os tratamentos e médias entre os períodos avaliados.

Tabela 4 Disponibilidade em $\mathrm{kg} / \mathrm{ha}$ de matéria seca verde total (MSVT) do capim marandu consorciado com amendoim forrageiro e do capim marandu adubado com $120 \mathrm{~kg} / \mathrm{N} / \mathrm{ha}$

\begin{tabular}{lcccc}
\hline Períodos & Consórcio & Adubação & Média & CV $(\%)$ \\
\hline $1^{\circ}$ Período & 2.533 & 2.148 & $2.340^{\mathrm{A}}$ & 21,06 \\
$2^{\mathrm{o}}$ Período & 1.715 & 1.397 & $1.556^{\mathrm{B}}$ & 8,85 \\
$3^{\mathrm{o}}$ Período & 2.300 & 1.716 & $2.008^{\mathrm{A}}$ & 6,89 \\
$4^{\mathrm{o}}$ Período & 2.442 & 2.041 & $2.242^{\mathrm{A}}$ & 10,91 \\
$5^{\mathrm{o}}$ Período & 2.320 & 1.937 & $2.129^{\mathrm{A}}$ & 16,03 \\
$6^{\mathrm{o}}$ Período & 1.827 & 1.463 & $1.645^{\mathrm{B}}$ & 13,32 \\
\hline Média & $2.190^{\mathrm{a}}$ & $1.784^{\mathrm{b}}$ & & 14,61 \\
\hline
\end{tabular}

Médias seguidas de letras distintas, minúsculas na linha e maiúsculas na coluna, diferem $(\mathrm{P}<0,05)$ entre si, pelo teste SNK.. 
Rev. Bras. Saúde Prod. Anim., Salvador, v.16, n.3, p.643-657 jul./set.., $2015 \quad \underline{\text { http://www.rbspa.ufba.br }}$ ISSN 15199940

Ao se avaliar a disponibilidade de matéria seca verde total (MSVT), composta da folha + colmo verde do capim marandu + a planta inteira verde do amendoim forrageiro cv. Belmonte, notou-se significância estatística $(\mathrm{P}<0,05)$ para a média dos tratamentos, cujo tratamento com o consórcio apresentou a maior média com $2.190 \mathrm{~kg}$ de matéria seca verde o total por hectare.

$\mathrm{Na}$ comparação entre a média dos períodos, houve significância estatística $(\mathrm{P}<0,05)$, na qual o segundo e o sexto períodos apresentaram as menores disponibilidades.

A pastagem constituída do consórcio de capim marandu com amendoim forrageiro apresentou a maior oferta de forragem verde, sendo, aproximadamente, tal oferta $23 \%$ superior à obtida na pastagem da mesma gramínea fertilizada com $120 \mathrm{~kg} / \mathrm{N} / \mathrm{ha}$. A presença da leguminosa propiciou um aumento de oferta de matéria seca de forragem verde, comprovando que a constante incorporação de nitrogênio e um manejo da pastagem de forma a obedecer ao período de descanso correto, favorecem a rebrota da planta, além de que, devido ao sistema de crescimento ser estolonífero, a mesma ocupa os espaços abertos entre a gramínea, aumentando, assim, a oferta de material verde na área (Tabela 4).

Avaliando-se o percentual de proteína bruta $(\mathrm{PB} \%)$ na matéria seca de forragem verde nas pastagens de capim marandu consorciado com o amendoim forrageiro e capim marandu fertilizado com $120 \mathrm{~kg} / \mathrm{N} / \mathrm{ha}$, obteve-se interação significativa $\quad(\mathrm{P}<0,05) \quad$ entre os tratamentos e os períodos avaliados (Tabela 5).

Tabela 5. Teores de proteína bruta do capim marandu consorciado com o amendoim forrageiro ou adubado com $120 \mathrm{~kg} / \mathrm{N} / \mathrm{ha}$

\begin{tabular}{lcccc}
\hline Períodos & Consórcio & Adubação & Média & CV $(\%)$ \\
\hline $1^{\circ}$ Período & $9,9^{\mathrm{aCD}}$ & $8,9^{\mathrm{aC}}$ & 9,3 & 9,61 \\
$2^{\circ}$ Período & $15,1^{\mathrm{aA}}$ & $12,8^{\mathrm{BB}}$ & 14,0 & 13,28 \\
$3^{\circ}$ Período & $13,7^{\mathrm{bAB}}$ & $15,8^{\mathrm{aA}}$ & 14,8 & 11,38 \\
$4^{\circ}$ Período & $8,3^{\mathrm{aD}}$ & $6,9^{\mathrm{aD}}$ & 7,6 & 11,06 \\
$5^{\circ}$ Período & $11,6^{\mathrm{aBC}}$ & $11,3^{\mathrm{aB}}$ & 11,5 & 9,96 \\
$6^{\circ}$ Período & $11,8^{\mathrm{aBC}}$ & $10,8^{\mathrm{aB}}$ & 11,3 & 10,78 \\
\hline Média & 11,7 & 11,1 & 11,63 \\
\hline Médias seguidas de letras distintas, minúsculas na linha e maiúsculas na coluna, diferem $(\mathrm{P}<0,05)$ entre \\
si, pelo teste SNK.
\end{tabular}

O segundo período apresentou menor disponibilidade de forragem verde, contudo, o teor de PB foi de $15,1 \%$ no tratamento do consórcio. Apesar de a planta passar por uma menor precipitação pluviométrica, diminuindo seu desenvolvimento, ela apresentou uma maior concentração dos nutrientes em seus tecidos, principalmente $\mathrm{o}$ nitrogênio, já que este nutriente não pode ser usado para incrementar a produção de forragem devido às limitações climáticas (Tabela 1). Dados apresentados por Oliveira et. al. (2009) descreveram um menor crescimento das plantas forrageiras durante o período hibernal, fazendo com que a mesma apresente um maior teor nutricional. Já no capim marandu fertilizado com nitrogênio, a maior percentagem de $\mathrm{PB}$ ocorreu na forragem verde obtida no terceiro período, justamente na ocasião 
Rev. Bras. Saúde Prod. Anim., Salvador, v.16, n.3, p.643-657 jul./set.., $2015 \quad \underline{\text { http://www.rbspa.ufba.br }}$ ISSN 15199940

em que foi realizada a fertilização de $40 \mathrm{~kg}$ de N/ha.

No quarto período, as condições climáticas favoreceram uma maior oferta de matéria seca de forragem verde, tanto na pastagem consorciada como na fertilizada com nitrogênio, aliadas aos efeitos da adubação nitrogenada ocorrida no período anterior, na pastagem fertilizada. Consequentemente, houve um incremento de produção de forragem (Tabela 4), o que permitiu que a planta utilizasse todo o nitrogênio disponível para o seu crescimento, obtendo, assim, o maior dispêndio de nutrientes para promoção do crescimento das plantas, resultando em teores de $\mathrm{PB}$ de $8,3 \%$ e $6,9 \%$ para a pastagem consorciada e fertilizada com nitrogênio, respectivamente.

Os teores de nutrientes digestíveis totais (NDT) e de fibra em detergente neutro (FDN) foram avaliados nas duas pastagens e por seis períodos, não sendo observadas diferenças significativas $(\mathrm{P}>0,05)$ para os tratamentos avaliados (Tabela 6). O teor de FDN está diretamente ligado ao consumo do alimento, sendo considerado como um limitante quanto ao fator de enchimento do rumem.

Tabela 6. Teores de nutrientes digestíveis totais (NDT) e fibra em detergente neutro (FDN) em matéria seca verde do capim marandu consorciado ou adubado com $120 \mathrm{~kg} / \mathrm{N} / \mathrm{ha}$ (MSVT)

\begin{tabular}{|c|c|c|c|c|}
\hline \multicolumn{5}{|c|}{ Nutrientes digestíveis totais (NDT) } \\
\hline Períodos & Consórcio & Adubação & Média & CV $(\%)$ \\
\hline $1^{\circ}$ Período & 53,7 & 53,6 & 53,6 & 0,71 \\
\hline $2^{\circ}$ Período & 54,7 & 52,1 & 53,4 & 37,32 \\
\hline $3^{\circ}$ Período & 57,6 & 55 & 56,3 & 3,56 \\
\hline $4^{\circ}$ Período & 53,7 & 53,5 & 53,6 & 1,47 \\
\hline $5^{\circ}$ Período & 54,1 & 54,1 & 54,1 & 1,55 \\
\hline $6^{\circ}$ Período & 53,7 & 53,3 & 53,5 & 1,88 \\
\hline Média & 54,6 & 51,9 & - & 13,98 \\
\hline \multicolumn{5}{|c|}{ Fibra em detergente neutro (FDN) } \\
\hline Períodos & Consórcio & Adubação & Média & \\
\hline $1^{\circ}$ Período & 75,8 & 76,0 & 75,9 & 0,75 \\
\hline $2^{\circ}$ Período & 74,3 & 74,4 & 74,4 & 2,41 \\
\hline $3^{\circ}$ Período & 77,5 & 72,5 & 75,0 & 9,84 \\
\hline $4^{\circ}$ Período & 75,8 & 76,1 & 76,0 & 1,56 \\
\hline $5^{\circ}$ Período & 75,2 & 75,2 & 75,2 & 1,57 \\
\hline $6^{\circ}$ Período & 75,8 & 76,4 & 76,1 & 1,83 \\
\hline Média & 75,7 & 75,1 & & 4,32 \\
\hline
\end{tabular}

Médias seguidas de letras distintas, minúsculas na linha e maiúsculas na coluna, diferem $(\mathrm{P}<0,05)$ entre si, pelo teste SNK.

A fixação biológica do nitrogênio atmosférico pelo amendoim forrageiro e a fertilização nitrogenada, disponibilizadas para as pastagens de capim marandu, não influenciaram os teores dos nutrientes digestíveis totais e fibra em detergente neutro, ficando em valores médios de $53,3 \%$ e $75,4 \%$, respectivamente.

Avaliando, em separado, a leguminosa, ou seja, o amendoim forrageiro, é possível observar que os teores de $\mathrm{PB}$ variaram nos períodos em estudo $(\mathrm{P}<0,05)$, sendo observados teores 
Rev. Bras. Saúde Prod. Anim., Salvador, v.16, n.3, p.643-657 jul./set.., $2015 \quad \underline{\text { http://www.rbspa.ufba.br }}$ ISSN 15199940 http://dx.doi.org/10.1590/S1519-99402015000300015

inferiores na leguminosa no quarto período (Tabela 7). Os resultados foram superiores aos obtidos por Lolato et al. (2012), que obtiveram teor médio de PB de $17,1 \%$ para o amendoim forrageiro. Os teores de NDT não apresentaram diferenças estáticas nos períodos estudados. Estudos apresentados por Lenzi et al. (2009) relataram que houve uma limitação do $A$. pintoi em tolerar estresse hídrico, ao contrário de muitas leguminosas tropicais, que têm maior participação na alimentação dos animais durante a época seca do ano; com essa baixa tolerância ocorre a diminuição da participação do $A$. pintoi no pasto, já que sua maior contribuição se dá nos períodos de maior ocorrência de chuvas.

Tabela 7. Teores de Proteína Bruta (PB \%), nutrientes digestíveis totais (NDT\%) e fibra em detergente neutro (FDN\%) do amendoim forrageiro nos períodos avaliados

\begin{tabular}{lcccc}
\hline Períodos & PB \% & NDT \% & FDN\% & CV (\%) \\
\hline $1^{\circ}$ Período & $24^{\mathrm{B}}$ & $52^{\mathrm{B}}$ & $67^{\mathrm{A}}$ & 3,98 \\
$2^{\mathrm{o}}$ Período & $26^{\mathrm{AB}}$ & $54^{\mathrm{B}}$ & $66^{\mathrm{A}}$ & 3,49 \\
$3^{\mathrm{o}}$ Período & $25^{\mathrm{B}}$ & $56^{\mathrm{B}}$ & $59^{\mathrm{BC}}$ & 6,37 \\
$4^{\mathrm{o}}$ Período & $22^{\mathrm{C}}$ & $56^{\mathrm{B}}$ & $56^{\mathrm{C}}$ & 2,61 \\
$5^{\mathrm{o}}$ Período & $27^{\mathrm{A}}$ & $63^{\mathrm{A}}$ & $62^{\mathrm{AB}}$ & 4,49 \\
$6^{\mathrm{o}}$ Período & $25^{\mathrm{AB}}$ & $64^{\mathrm{A}}$ & $61^{\mathrm{AB}}$ & 5,68 \\
\hline Média & 25 & 58 & 62 & \\
\hline $\mathrm{CV}(\%)$ & 5,03 & 4,46 & 4,97 & \\
\hline
\end{tabular}

Médias seguidas de letras distintas, maiúsculas na coluna, diferem $(\mathrm{P}<0,05)$ entre si, pelo teste SNK.

$\mathrm{Na}$ análise da variável ganho médio diário (GMD), foi verificada interação significativa entre os tratamentos e os períodos avaliados $(\mathrm{P}<0,05)$. No tratamento com o consórcio, o primeiro período apresentou o maior desempenho, com média de $0,62 \mathrm{~kg} /$ dia, diferindo-se estatisticamente do tratamento com a adubação (Tabela 8). A presença da leguminosa proporcionou aos animais a oferta de um alimento com maior teor de proteína, propiciando um maior desenvolvimento, já que, de acordo com o peso dos animais, os mesmos apresentavam uma maior exigência proteica por estarem em crescimento.

Tabela 8. Ganho médio diário GMD (kg/dia) de bovinos criados em pastagem de capim marandu consorciada com o amendoim forrageiro ou adubado com $120 \mathrm{~kg} / \mathrm{N} /$

\begin{tabular}{lcccc}
\hline Períodos & Consórcio & Adubação & Média & CV $(\%)$ \\
\hline $1^{\circ}$ Período & $0,62^{\mathrm{aA}}$ & $0,49^{\mathrm{bA}}$ & 0,56 & 8,56 \\
$2^{\circ}$ Período & $0,41^{\mathrm{aB}}$ & $0,51^{\mathrm{aA}}$ & 0,49 & 19,33 \\
$3^{\mathrm{o}}$ Período & $0,49^{\mathrm{aB}}$ & $0,53^{\mathrm{aA}}$ & 0,51 & 15,70 \\
$4^{\mathrm{o}}$ Período & $0,29^{\mathrm{aC}}$ & $0,31^{\mathrm{aB}}$ & 0,30 & 23,97 \\
$5^{\mathrm{o}}$ Período & $0,41^{\mathrm{aB}}$ & $0,50^{\mathrm{aA}}$ & 0,46 & 17,05 \\
$6^{\circ}$ Período & $0,20^{\mathrm{aC}}$ & $0,20^{\mathrm{aB}}$ & 0,20 & 22,15 \\
\hline Média & 0,40 & 0,42 & & 17,02 \\
\hline
\end{tabular}

Médias seguidas de letras distintas, minúsculas na linha e maiúsculas na coluna, diferem $(\mathrm{P}<0,05)$ entre si, pelo teste SNK. 
Rev. Bras. Saúde Prod. Anim., Salvador, v.16, n.3, p.643-657 jul./set.., $2015 \quad \underline{\text { http://www.rbspa.ufba.br }}$ ISSN 15199940

No tratamento com o consórcio, o segundo, terceiro e quinto períodos, com médias de 0,$41 ; 0,49$ e $0,41 \mathrm{~kg} / \mathrm{dia}$, respectivamente, não se diferiram estatisticamente $(\mathrm{P}>0,05)$. No tratamento com a adubação, o primeiro, segundo, terceiro e quinto períodos, com médias de 0,$49 ; \quad 0,51 ; \quad 0,53$ e $0,50 \mathrm{~kg} / \mathrm{dia}$, respectivamente, foram considerados semelhantes estatisticamente $(\mathrm{P}>0,05)$, conforme demonstrado na Tabela 8 .

O quarto e sexto períodos, para os dois tratamentos, foram os que apresentaram as menores taxas de ganho de peso. Apesar do quarto período ter um maior acúmulo de forragem, esse acúmulo ocorreu no final do período devido a uma maior ocorrência de chuvas. No sexto período, o ganho de peso baixo é reflexo de uma menor disponibilidade de forragem. Aliado a essa baixa oferta de forragem, o baixo ganho de peso no sexto período pode ser explicado pelo fato dos animais já estarem atingindo o peso de abate. Ao atingir o peso de abate, os animais já se apresentam com a carcaça desenvolvida, iniciando a deposição de gordura na carcaça, passando a ser mais exigentes em energia ou NDT, tornando, assim, o ganho de peso menor em condições de alimentação somente a pasto (Tabela 8). Ribeiro et. al. (2008) obtiveram ganho médio diário de $0,514 \mathrm{~kg} /$ dia no inverno; $0,546 \mathrm{~kg} / \mathrm{dia}$, na primavera; $0,610 \mathrm{~kg} / \mathrm{dia}$, no verão e $0,150 \mathrm{~kg} / \mathrm{dia}$, no outono; e Paris et al. (2004), trabalhando na mesma pastagem e área experimental, de fevereiro a maio (verão+outono), obtiveram a média do GMD de $0,511 \mathrm{~kg}$, em períodos semelhantes ao ano do presente estudo, apresentando ganhos maiores que observados neste trabalho.

Avaliando o número de animais em pastejo ao dia (NAD), foi observada a interação estatística significativa $(\mathrm{P}<0,05)$ entre os tratamentos e os períodos avaliados, conforme apresentado na Tabela 9.

Tabela 9. Número de animais pastejando ao dia (NAD) em pastagem do capim marandu consorciada com o amendoim forrageiro ou adubada com $120 \mathrm{~kg} / \mathrm{N} / \mathrm{ha}$

\begin{tabular}{lcccc}
\hline Períodos & Consórcio & Adubação & Média & CV $(\%)$ \\
\hline $1^{\mathrm{o}}$ Período & $5,4^{\mathrm{aA}}$ & $4,4^{\mathrm{bA}}$ & 4,9 & 9,82 \\
$2^{\mathrm{o}}$ Período & $3,8^{\mathrm{aC}}$ & $4,3^{\mathrm{aA}}$ & 4,0 & 10,51 \\
$3^{\mathrm{o}}$ Período & $3,2^{\mathrm{aC}}$ & $3,1^{\mathrm{aB}}$ & 3,1 & 8,43 \\
$4^{\mathrm{o}}$ Período & $3,5^{\mathrm{aC}}$ & $3,0^{\mathrm{aB}}$ & 3,3 & 12,56 \\
$5^{\mathrm{o}}$ Período & $4,6^{\mathrm{aB}}$ & $4,8^{\mathrm{aA}}$ & 4,7 & 8,43 \\
$6^{\mathrm{o}}$ Período & $3,5^{\mathrm{aC}}$ & $3,5^{\mathrm{aB}}$ & 3,5 & 16,50 \\
\hline Média & 4,0 & 3,8 & & 11,12 \\
\hline
\end{tabular}

Médias seguidas de letras distintas, minúsculas na linha e maiúsculas na coluna, diferem $(\mathrm{P}<0,05)$ entre si, pelo teste SNK.

No tratamento do consórcio, o primeiro período teve um maior número de animais pastejando, com média de 5,4. O quinto período foi o que apresentou a segunda maior média, sendo que os demais períodos, segundo, terceiro, quarto e sexto, foram considerados semelhantes estatisticamente. No tratamento adubação, o primeiro, segundo e o quinto períodos obtiveram as melhores médias, sendo considerados semelhantes estatisticamente, seguidos do terceiro, quarto e sexto períodos. A realização das adubações no primeiro e 
Rev. Bras. Saúde Prod. Anim., Salvador, v.16, n.3, p.643-657 jul./set.., $2015 \quad \underline{\text { http://www.rbspa.ufba.br }}$ ISSN 15199940

quinto foi traduzida em uma maior oferta de forragem verde, sendo que no terceiro período, mesmo com a realização da adubação de cobertura, houve prejuízo, devido aos baixos índices pluviométricos ocorridos, conforme Figura 1.

Com o desenvolver do experimento, os animais foram ganhando peso, aumentando, assim, o peso corporal e, consequentemente, o consumo de matéria seca da forragem que sempre foi ofertada constantemente em $4,0 \%$ do peso corporal. Com o aumento do peso corporal e o aumento do consumo, houve uma diminuição no número de animais em pastejo para que fosse mantida essa oferta de forragem (Tabela 9).

Os dados apresentados neste estudo vão de encontro aos apresentados por Barbero et al. (2010), que não encontraram interação entre os tratamentos e os períodos para a variável número de animais em pastejo.

A avaliação estatística para os parâmetros da taxa de lotação apresentaram efeito significativo $(\mathrm{P}<0,05)$ entre as médias dos períodos, conforme Tabela 10.

$\mathrm{O}$ primeiro e terceiro períodos foram os que apresentaram as maiores médias de lotação, seguidos do segundo, quarto e quinto períodos, sendo esses os que apresentaram as maiores ofertas de matéria seca verde total, como a taxa de lotação, que foi determinada em detrimento da oferta de forragem constante de $4,0 \%$ do peso corporal, justificando essa maior taxa de lotação nesses períodos.

Ribeiro et. al. (2008), avaliando a produção de forragem e desempenho animal em pastagens consorciadas com Arachis pintoi nas quatro estações do ano, obtiveram taxa de lotação de 1,47 $\mathrm{UA} /$ dia no inverno, 2,02 UA/dia na primavera, 2,92 UA/dia no verão e 2,72 UA/dia no outono, resultados esses, inferiores aos obtidos no presente estudo (Tabela 10).

Tabela 10. Taxa de lotação de novilhos em UA/ha, sob pastejo em capim marandu consorciado com o amendoim forrageiro ou adubado com $120 \mathrm{~kg} / \mathrm{N} / \mathrm{ha}$

\begin{tabular}{lcccc}
\hline Períodos & Consórcio & Adubação & Média & CV \\
\hline $1^{\circ}$ Período & 3,9 & 4,2 & $4,0^{\mathrm{A}}$ & 22,74 \\
$2^{\circ}$ Período & 3,0 & 2,5 & $2,8^{\mathrm{BC}}$ & 11,62 \\
$3^{\circ}$ Período & 4,2 & 3,6 & $3,9^{\mathrm{A}}$ & 12,52 \\
$4^{\circ}$ Período & 3,0 & 2,7 & $2,9^{\mathrm{BC}}$ & 10,28 \\
$5^{\circ}$ Período & 3,3 & 3,0 & $3,1^{\mathrm{B}}$ & 7,80 \\
$6^{\circ}$ Período & 2,5 & 2,2 & $2,3^{\mathrm{C}}$ & 12,99 \\
\hline Média & 3,3 & 3,0 & & 15,35 \\
\hline
\end{tabular}

Médias seguidas de letras distintas, maiúsculas na coluna, diferem $(\mathrm{P}<0,05)$ entre si, pelo teste $\mathrm{SNK}$.

O ganho peso corporal por período (GPC/período) de novilhos em pasto de capim marandu consorciado com amendoim forrageiro ou adubado apresentou interação significativa $(\mathrm{P}<0,05)$ entre tratamento e os períodos avaliados (Tabela 11).
$\mathrm{Na}$ comparação entre os tratamentos, o primeiro período do tratamento consórcio apresentou diferença estatística $(\mathrm{P}<0,05)$ com 307 quilos de ganho de peso corporal, e no segundo período do tratamento, adubação com média de 200 quilos de ganho de peso corporal. No quarto e sexto períodos, para os dois 
Rev. Bras. Saúde Prod. Anim., Salvador, v.16, n.3, p.643-657 jul./set.., $2015 \quad \underline{\text { http://www.rbspa.ufba.br }}$

tratamentos, houve os menores ganhos de peso corporal. O ganho de peso corporal foi calculado multiplicando o ganho médio diário pelo número de animais em pastejo em cada período, com isso, o primeiro período do tratamento consórcio e segundo período do tratamento adubação apresentaram os maiores ganhos de peso médio diário, e o primeiro obteve o maior número de animais em pastejo (Tabelas 8 e 9).

Barbero et. al. (2010) observaram, em Coastcross consorciado com amendoim, ganho de peso corpóreo de $96 \mathrm{~kg}$ no outono, $156 \mathrm{~kg}$ na primavera, $365 \mathrm{~kg}$ no verão e $119 \mathrm{~kg}$ no inverno; valores superiores aos apresentados neste trabalho, conforme Tabela 11.

Tabela 11. Ganho peso corpóreo por período (GPC/período) de novilhos em pasto de capim marandu consorciado com amendoim forrageiro ou adubado com $120 \mathrm{~kg} / \mathrm{N} / \mathrm{ha}$

\begin{tabular}{lcccc}
\hline Períodos & Consórcio & Adubação & Média & C.V. \\
\hline $1^{\circ}$ Período & $307^{\mathrm{aA}}$ & $200^{\mathrm{BA}}$ & 255 & 18,22 \\
$2^{\circ}$ Período & $148^{\mathrm{bB}}$ & $200^{\mathrm{aA}}$ & 174 & 16,74 \\
$3^{\mathrm{o}}$ Período & $138^{\mathrm{aB}}$ & $143^{\mathrm{aB}}$ & 140 & 14,88 \\
$4^{\circ}$ Período & $89^{\mathrm{aC}}$ & $83^{\mathrm{aC}}$ & 86 & 20,95 \\
$5^{\circ}$ Período & $176^{\mathrm{aB}}$ & $218^{\mathrm{aA}}$ & 197 & 16,59 \\
$6^{\circ}$ Período & $67^{\mathrm{aC}}$ & $68^{\mathrm{aC}}$ & 67 & 33,19 \\
\hline Média & 154 & 156 & & 19,43 \\
\hline Médias seguidas de letras distintas, minúsculas na linha e maiúsculas na coluna, diferem $(\mathrm{P}<0,05)$ \\
entre si, pelo teste SNK.
\end{tabular}

Constam, na Tabela 12, os resultados referentes aos pesos vivo sem jejum, peso de carcaça quente e fria, perda de peso por resfriamento, comprimentos de carcaça e comprimento de perna, espessura de coxão e gordura de cobertura e área de olho de lombo das carcaças dos tratamentos estudados.

Não houve diferenças estatísticas para nenhuma das variáveis avaliadas $(\mathrm{P}>0,05)$, em relação aos tratamentos consórcio e adubação.

Com o sistema de alimentação somente a pasto e com uma oferta constante de $4 \%$ do peso corporal de matéria seca de material verde, os animais atingiram o peso de abate na mesma época e com peso corporal semelhante $(\mathrm{P}>0,050)$. Após o abate, os animais apresentaram peso da carcaça quente e o peso da carcaça fria semelhantes $(\mathrm{P}>0,05)$.
$\mathrm{Na}$ Tabela 12, estão representados $\mathrm{o}$ peso vivo sem jejum, peso de carcaça fria, perda de peso por resfriamento, comprimentos de carcaça e perna, espessura de coxão e gordura de cobertura e área de olho de lombo de bovinos de corte submetidos a pastejo em pastagem consorciada e adubada.

Os animais tiveram pesos de carcaça quentes e frias semelhantes, assim como a espessura de gordura $(\mathrm{P}>0,05)$. A perda por resfriamento é afetada pela cobertura de gordura, que protege durante o resfriamento, evitando a perda da água durante o processo. Isso ficou evidenciado pelos resultados apresentados neste estudo, nos quais as variáveis avaliadas não apresentaram diferenças estatísticas $(\mathrm{P}>0,05)$, conforme Tabela 12. 
Rev. Bras. Saúde Prod. Anim., Salvador, v.16, n.3, p.643-657 jul./set.., $2015 \quad \underline{\text { http://www.rbspa.ufba.br }}$ ISSN 15199940 http://dx.doi.org/10.1590/S1519-99402015000300015

Tabela 12. Peso vivo sem jejum, peso de carcaça fria, perda de peso por resfriamento, comprimentos de carcaça e perna, espessura de coxão e gordura de cobertura e área de olho de lombo de bovinos de corte submetidos à pastejo em pastagem de capim marandu consorciada com amendoim forrageiro ou adubada com $120 \mathrm{~kg} / \mathrm{N} / \mathrm{ha}$

\begin{tabular}{ccccc}
\hline Item & Consórcio & Adubação & Média & CV \\
\hline PVSJ $^{1}$ & 510,86 & 505,00 & 508,15 & 6,41 \\
PCQ $^{2}$ & 276,29 & 273,48 & 274,99 & 7,51 \\
PCF $^{3}$ & 270,37 & 267,22 & 268,15 & 7,46 \\
PPR $^{4}$ & 2,14 & 2,28 & 2,21 & 1,42 \\
$\mathrm{CC}^{5}$ & 144,64 & 146,92 & 145,69 & 5,16 \\
$\mathrm{CP}^{6}$ & 81,71 & 82,35 & 82,01 & 3,43 \\
$\mathrm{EC}^{7}$ & 25,30 & 27,10 & 26,13 & 6,55 \\
$\mathrm{EG}^{8}$ & 5,47 & 5,12 & 5,31 & 2,44 \\
$\mathrm{AOL}^{9}$ & 71,00 & 74,83 & 72,77 & 7,09 \\
\hline
\end{tabular}

${ }^{1}$ Peso vivo sem jejum; ${ }^{2}$ Peso de carcaça quente; ${ }^{3}$ Peso de carcaça fria; $;{ }^{4}$ Perda de peso por resfriamento;

${ }^{5}$ Comprimento de carcaça; ${ }^{6}$ Comprimento de perna; ${ }^{7}$ Espessura de Coxão; ${ }^{8}$ Espessura de gordura; 9Área de olho de lombo.

Médias seguidas de letras distintas, minúsculas na linha, diferem $(\mathrm{P}<0,05)$ entre si, pelo teste SNK.

Para as variáveis de comprimento de carcaça, comprimentos de perna, espessura do coxão e área de olho de lombo, também não foram observadas diferenças estatísticas $(\mathrm{P}>0,05)$, demonstrando uma uniformidade das unidades experimentais e de um desenvolvimento similar entre os tratamentos, conforme Tabela 12.

Segundo Costa et al. (2002), a área de olho de lombo (AOL) expressa a musculosidade da carcaça, estando, dessa forma, diretamente correlacionada ao seu peso.

$\mathrm{Na}$ Tabela 13 estão expressas as médias da avaliação da coloração, textura, marmoreio e conformação de carcaça do Longissimus dorsi de bovinos de corte, submetidos a pastejo em braquiária brizantha consorciada com amendoim forrageiro ou adubada com $120 \mathrm{Kg} / \mathrm{N} / \mathrm{ha}$.

Tabela 13. Coloração, textura, marmoreio e conformação de carcaça do Longissimus dorsi de bovinos de corte, submetidos a pastejo em capim marandu consorciado com amendoim forrageiro ou adubado com $120 \mathrm{~kg} / \mathrm{N} / \mathrm{ha}$

\begin{tabular}{lcccc}
\hline Item & Consórcio & Adubação & Média & CV \\
\hline Coloração & $3,86^{\mathrm{a}}$ & $3,83^{\mathrm{a}}$ & 3,85 & 2,17 \\
Textura & $3,43^{\mathrm{a}}$ & $3,50^{\mathrm{a}}$ & 3,46 & 1,56 \\
Marmoreio & $6,57^{\mathrm{a}}$ & $5,83^{\mathrm{a}}$ & 6,23 & 2,40 \\
Conformação & $13,85^{\mathrm{b}}$ & $14,83^{\mathrm{a}}$ & 14,31 & 4,05 \\
\hline
\end{tabular}

Médias seguidas de letras distintas, minúsculas na linha, diferem $(\mathrm{p}<0,05)$ entre si, pelo teste SNK. 
Rev. Bras. Saúde Prod. Anim., Salvador, v.16, n.3, p.643-657 jul./set.., $2015 \quad \underline{\text { http://www.rbspa.ufba.br }}$ ISSN 15199940

Não foi observada diferença estatística $(\mathrm{P}>0,05)$ entre as variáveis coloração, textura e marmoreio.

O marmoreio é um fator visual importante para o consumidor, pelo fato de estar intimamente relacionado com características sensoriais, como maciez, palatabilidade e suculência (MARTIN NIETO, 2004). Com isso, fica demonstrado que o sistema de alimentação a pasto não implica em diferenças no acabamento da carcaça quanto às variáveis coloração, textura e marmoreio, que são aquelas observadas pelos consumidores na hora da escolha do produto final, conforme Tabela 13.

Houve diferença estatística $(\mathrm{P}<0,05)$ para conformação. A conformação é uma medida subjetiva utilizada para avaliação da deposição de tecido muscular, buscando avaliar o rendimento de parte comestível. Ao apresentar uma maior pontuação na avaliação da conformação para o tratamento adubação, entende-se que esse tratamento tende a apresentar um maior rendimento da parte comestível que o tratamento consórcio, conforme Tabela 13.

O consórcio do amendoim forrageiro cv. Belmonte pode ser utilizado em substituição à adubação com $120 \mathrm{~kg} / \mathrm{N} / \mathrm{ha}$, pois garante o mesmo ganho de peso por animal, sem alterar as características comerciais das carcaças.

\section{REFERÊNCIAS}

BARBERO, L.M.; CECATO, U.; LUGÃO, S.M.B.; GOMES, J.A.N; LIMÃO, V.A.; ABRAHÃO, J.J.S.; ROMA, C.F.C. Produção animal e valor nutritivo da forragem de pastagem de coastcross consorciada com amendoim forrageiro. Arquivo

Brasileiro de Medicina Veterinária e Zootecnia, v.62, n.3, p.645-653, 2010.
BARCELLOS, A.O.; RAMOS, A.K.B.; VILELA, L.; MARTHA JUNIOR, G.B. Sustentabilidade da produção animal baseada em pastagens consorciadas e no emprego de leguminosas exclusivas, na forma de banco de proteína, nos trópicos brasileiros. Revista Brasileira de Zootecnia, v.37, p.51-67, 2008. Supl.

CAVALLINI, M.C.; ANDREOTTI, M.; OLIVEIRA, L.L.; PARIZ, C.M.; CARVALHO, M. de P. e. Relações entre produtividade de Brachiaria brizantha e atributos físicos de um Latossolo do Cerrado. Revista Brasileira de Ciência do Solo, v.34, n.4, p.1007-1015, 2010.

CHANDLER, P. Energy prediction of feeds by forage testing explorer.

Feedstuffs, v.62, n. 36, p.12, 1990.

COSTA, E.C.; RESTLE, J.; VAZ, F.N.; ALVES FILHO, D.C.; BERNARDES, R.A.L.C.; KUSS, F. Características da carcaça de novilhos Red Angus superprecoces abatidos com diferentes pesos. Revista Brasileira de

Zootecnia, v.31, n.1, p.119-128, 2002.

FERNANDES, L.O.; REIS, R.A.;

PAES, J.M.V. Efeito da suplementação no desempenho de bovinos de corte em pastagem de Brachiaria brizantha cv. Marandu. Ciência \& Agrotecnologia, v.34, n.1, p.240-248, 2010.

LENZI, A.; CECATO, U.; MACHADO

FILHO, L.C.P.; GASPARINO, E.;

ROMA, C.F.C.; BARBERO, L.M.;

LIMÃO, V.A. Produção e qualidade do pasto de coastcross consorciado ou não com amendoim forrageiro com ou sem aplicação de nitrogênio. Arquivo

Brasileiro de Medicina Veterinária e Zootecnia, v.61, n.4, p.918-926, 2009. 
Rev. Bras. Saúde Prod. Anim., Salvador, v.16, n.3, p.643-657 jul./set.., $2015 \quad \underline{\text { http://www.rbspa.ufba.br }}$ ISSN 15199940 http://dx.doi.org/10.1590/S1519-99402015000300015

LOLATO, R.O.; CECATO, U.; RODRIGUES, A. M.; FAVERI, J.C.; SANTOS, G.T. dos; LUGÃO, S.M.B.; BELONI, T, Composição botânica e química da Coastcross consorciada ou não com Arachis pintoi, com e sem nitrogênio, Revista Brasileira de Saúde e Produção Animal [online], v.13, n.1, p.47-61 2012.

MARTIN NIETO, L. Fatores genéticos que alteram a qualidade da carne e do leite em ruminantes. In: PRADO, I.N. Conceitos sobre a produção com qualidade de carne e leite. Maringá: EDUEM, 2004. 301p.

MULLER, L. Normas para avaliação de carcaça e concurso de carcaças de novilhos. 2.ed. Santa Maria: Universidade Federal de Santa Maria, 1980. 31p.

OLIVEIRA, I.P.; COSTA, K.A.P.; FAQUIN, V.; MACIEL, G.A.; NEVES, B.P.; MACHADO, E.L. Efeitos de fontes de cálcio no desenvolvimento de gramíneas solteiras e consorciadas.

Ciência \& Agrotecnologia, v.33, n.2, p.592-598, 2009.

PARIS, W. Desempenho animal em pastagens de coastcross consorciada com Araquis pintoi (krapovickas y gregori) verão/outono. In: REUNIÃO ANUAL DA SOCIEDADE BRASILEIRA DE ZOOTECNIA, 41, 2004, Campo Grande. Anais... Campo Grande: Sociedade Brasileira de Zootecnia, 2004.

REZENDE, C.P.R.; PEREIRA, J.M.; PINTO, J.C; BORGES, A.M.F.; MUNIZ, J.A.; ANDRADE, I.F. da; EVANGELISTA, A.R. Estrutura do Pasto Disponível e do Resíduo PósPastejo em Pastagens de capimCameroon e Capim-Marandu. Revista Brasileira de Zootecnia, v.37, n.10, p.1742-1749, 2008.
RIBEIRO, O.L.; CECATO, U.; ROMA, C.F. da C.; FAVERI, J.C.; GOMES, J.A.N.; BARBERO, L.M. Produção de forragem e desempenho animal em pastagens de Coastcross consorciada ou não com Arachis pintoi, com e sem nitrogênio. Acta Scientiarum Animal Sciences, v.30, n.4, p.371-377, 2008.

\section{STATISTICAL ANALYSIS SYSTEM} - SAS. SAS User's guide: Statistics. Version 6.12. Cary, 1996. 956p.

SILVA, D.J.; QUEIROZ, A.C. Análise de alimentos: métodos químicos e biológicos. 3.ed. Viçosa: UFV, 2002. $235 \mathrm{p}$.

VAN SOEST, P.J. Voluntary intake relation to chemical composition and digestibility. Journal of Animal Science, v.24, p.834-844, 1994.

VOLPE, E.; MARCHETTI, M.E.; MACEDO, M.C.M.; JARDIM ROSA JUNIOR, E. Renovação de pastagem degradada com calagem, adubação e leguminosa consorciada, em Neossolo Quartzarênico. Acta Scientiarum:

Agronomy, v.30, n.1, p.131-138, 2008.

Data de recebimento: $18 / 03 / 2014$

Data de aprovação: 27/07/2015 